\title{
CLINICAL PATTERN OF NEONATAL INFECTIONS
}

\author{
(July 1991-June 1993)
}

M. N. Islam ${ }^{1}$, Abdul Hannan ${ }^{2}$, S. Zahid Hossain ${ }^{3}$, Md. Habibur Rahman ${ }^{4}$, S. A. Razzaque ${ }^{5}$,

\section{Summary}

Neonatal infection is an important cause of morbldity and mortality among infants. Clinical pattern of neonatal infection in the neonatal unit of Institute of Post Graduate Medicine \& Research (IPGM\&R), Dhaka has been reported. Out of total 2160 Neonatal admission from July 1991 to June $1993.320(14.8 \%)$ cases of neonatal infections were found. Septicaemia was the commonest type found in $118(5.5 \%)$ cases. Other infections included umbilical sepsis $(4.7 \%)$ Skin infections $(1.6 \%)$, Meningitis $(1.2 \%)$. Tetanus neonatrum were not included. Out of 320 cases, 20 patient died $(6.2 \%)$. Preterm, Low birth weight and birth asphyxia were the common risk factors.

\section{Introduction}

Infections are a frequent and important cause of morbidity and mortality in the neonatal period. As many as $2 \%$ of foetuses are infected in utero and upto $10 \%$ infants are infected during delivery or the first month of life ${ }^{1}$. Infection can be of two types. Early onset infection with perinatal pathogenesis whose usual onset is within 72 hOurs, whereas late neonatal infection is applied to infections those occur after one week. Neonatal infections vary from the trivial (Minor) which does not endanger life to profoundly damaging (Major) 2,3 . They may be subclinical br may kill the newborn. Among the major infections, septicaemia, pneumonia, diarrhoea, urinary tract infection (UTI), meningitis are common. Whereas minor infections, eg omphalitis, conjunctivitis are common problems. Neonatal septicaemia is a clinical syndrome characterized by signs of infection and documented by a positive blood culture in the first four weeks of life. The incidence of neonatal septicaemia has been estimated to range from 1 to 10 per 1000 live births. ${ }^{4,5}$ Early onset sepsis is more fulminant, commonly diagnosed within the first 48 hours and almost always during the first week of life. Late onset sepsis is more insidious. Despite the development of broad spectrum antlmicrobial agents and improved obstetric and paediatric care, septicaemia still contributes greatly to neonatal morbidity and mortality particularly in developing

\footnotetext{
1. Professor of Paediatrics \& Head of the Depatrment, IPGM\&R, Dhaka.

2. Associate Professor of Paediatrics, IPGM\&R, Dhaka.

3. Asstt. Prof. of Paediatrics, IPGM\&R, Dhaka.

4. Asstt. Prof. of Paediatrics, IPGM\&R, Dhaka.

5. Research Assistant, Paediatrics, IPGM\&R, Dhaka.
} 
countries. ${ }^{6}$ In Bangladesh, there is no definite study on the incidence, etiology. risk factors and prognosis of neonatal septicaemia but it is likely to be high in Bangladesh like other developing countries. ${ }^{7}$ Risk factors for development of neonatal sepsis are low birth weight. Apgar score less than 7 at 5 minutes, male sex, complication of labour e.g. prolonged labour, early rupture of membrane, malpresentation, complication of delivery like septic delivery, instrumental delivery and primary caesarian section and poor socio-economical conditions, 8-14 Group B strepto-coccus \& Escherichia Coli are the leading causes of sepsis. Other pathogens like Staphylococcus aureus, Klebsiella, Enterobacter, Group D streptococci and Pseudomonas aeroginosa, Strep pneumoniae, Nesseria meningitidis and Haemophilus influenzae are rarely encountered. Pneumonia is also common. ${ }^{15}$ Meningitis is one of the important variant of infections. It may be viral and bacterial. It is often associated with sepsis and is a cause of significant morbidity and mortality. 16,17,18 UTI in newborn is difficult to establish because, as many as $40 \%$ of the infections are asymptomatic. ${ }^{19}$ Diarrhoea is one of the important component of major infections and is a leading cause of illness and death among children of the developing countries. ${ }^{20}$ Among the minor infections omphalitis is the most common. ${ }^{21,22}$ The present study was carried out to know the clinical Pattern, etiological agents, risk factors and outcome of neonatal infections.

\section{Materials and Methods}

This study was done in the neonatal unit of the Department of Paediatric. Institute of Post Graduate Medicine and Research (IPGM\&R), Dhaka over a period of 2 years from July 1991 to June 1993. Three hundred twenty neonates with different types of infection were studied. TORCH infections, HIV, Hepatitis $B$ and neonatal tetanus were excluded from this study because these cases were admitted in a separate infectious disease hospital. A detailed prenatal, natal and post natal history with special emphasis on any predisposing factors for infection was taken and thorough clinical exmination was done in all the cases and were recorded. Patient's particulars like, redness around the umbilicus, umbilical discharge, fever, hypothermia, diarthoea, respiratory distress and feeding history were noted. Haemoglobin, total and differential count of WBC, Platelet counts were done in all patients, Swabs from the Umbilicus \& septic spots were sent for gram staining and $\mathrm{C} / \mathrm{S}$. Cultures of urine, stool \& blood were carried out in all cases, Radiographs of the chest and CSF examination were carried out whenever indicated clinically.

\section{Results}

Of the total 2160 neonatal admissions, 320 (14.8) had different types of infections. There were $212(66.2 \%)$ male and $108(33.8 \%)$ female babies. Age distribution is shown in Table-I. Mean age was 9.5 days. Table-II shows the various spectrum of infections. Septicaemia $118(36.87 \%)$, pneumonis 70 $(21.87 \%)$ and Meningitis $20(6.25 \%)$ were the major infections while Omphalitis $101(31.56 \%)$ and pemphigus $28(8.75 \%)$ were the minor infections in the 
studied Population. Table-III shows the age of onset of infections. Most patients with major or minor infections presented after $48 \mathrm{hr}$. Table-IV shows the risk factors of infection. Preterm low birth weight $228(71 \%)$ prolonged rupture of membrane $108(33.7 \%)$ birth asphyxia $46(14.3 \%)$ home delivery by untrained persons $52(16.2 \%)$ and use of unsterile blade to cut the cord $36(8 \%)$ cases were the risk factors in the study group. Fever $160(50 \%)$, respiratory distress $115(35.92 \%)$, Reluctant to feeds $112(35 \%)$, abdominal distension $102(31.8 \%)$, vomiting $98(30.6 \%)$, apnoic spells $28(8.7 \%)$, jaundice $36(11.2 \%)$, foul smelling umbilical discharge $80(25 \%)$, hypothermia $11(3.4 \%)$, Pemphigus $28(8.7 \%)$ and convulsions were the clinical presentation. Of course they had overlaping of clintcal presentations (Table-V)

Table-VI shows the organisms isolated from samples of blood, urine, stool and umbilical swabs. Blood culture done in 184 patients showed positive culture in 41 cases of which 35 showed E. coli and 6 patients showed staph aureus. Urine culture done in 184 cases yielded the growth of $\mathrm{E}$. coli in 15 patients, stool culture showed E. coli in 6 cases. Umbilical swab culture showed the growth of staph aureus in 75 cases and E. coli in 8 cases.

Table-VII shows total WBC count from $20,000-30,000 / \mathrm{cm}^{3}$ in $120(37.5 \%)$ and from 10,000 to $20,000 / \mathrm{cm}^{3}$ in $140(43.7 \%)$ cases. Table-VIII shows that 16 patients had hazy CSF with plenty of neutrophils. Gram staining showed the presence of 6 and 8 cases of Gram positive and Gram negative bacteria respectively. However culture did not show growth of any bacteria. Mean value of protein \& Sugar in CSF were 152 \& $22 \mathrm{mg} / \mathrm{dl}$ respectively.

Table-IX Shows the X-ray findings of the studied population. $30(42.8 \%)$ cases showed bilateral patchy opacities in the lung fields. 40 cases had opacities in both the lung flelds. Out of 320 cases of neonatal infection $20(6.2 \%)$ patients died in the hospital.

\section{Discussion}

Infections of the neonates are common causes of admission into the neonatal special care baby units. This study showed the pattern and predisposing fectors of neonatal infections in a tertiary centre with one of the largest neonatal units in Bangladesh. Out of 320 neonates, 184 had major infections and the remaining had minor infections, mostly Omphalitis. Septicaemia alone or in association with pneumonia, meningitis diarrhoea and UTI were the major infection. In this series septicaemia were found in $36.87 \%$, pneumonia in $(21.87 \%)$, meningitis in $(6.25 \%)$, diarrhoea in $(2.19 \%)$ UTI $(1.27 \%)$ cases (Table 1I). Majority of these patients were referred from different clinics, home and other hospitals. Various factors such as poor personal, hyglene, delay in recognition of infection, inappropriate or no treatment etc. could be the contributory factors for the higher incidence of infection. There was a preponderence of boys over girls in all types of infections. The male to female ratio was $2: 1$. The preponderence of male sex is postulated to be linked to the $\mathrm{X}$-linked factor ${ }^{23}$. It might be due to greater care given to the male child in our social set up 24 . In this study, most patients were low birth weight $(43.75 \%)$. Numerous studies have found LBW to be 
predispoding factor for neonatal infection. Low birth weight and preterm bables have low Ig.G as well as impaired cellular immunity. The risk for nosocomial infection is greatest in hospital. It is established that Umbilical stump is good media for luxuriant growth of variety of organisms ${ }^{25}$. But in this study it was observed that most of these patients had their umbilical cord cut aseptically.

Resuscitation was needed in $14.37 \%$ cases. In the major group of infections most of the neonates presented with Pyrexia other features being respiratory distress, reluctant to feed, abdominal distension, vomiting, Apnoic spells, Jaundice etc.

Pyrexia is one of the important features of septicaemia ${ }^{26}$, pneumonia, UTI ${ }^{27}$ and meningitis ${ }^{28}$. Fever (temperature above $38^{\circ} \mathrm{C}$ ) had been recorded in $50 \%$ of neonates with infection in this series. Respiratory distress was present in $35.92 \%$ cases which is similar to the findings of other workers $26,29,30$ Abdominal distension in neonates in this study was $31.87 \%$ which is higher than other studies. ${ }^{31,32}$.

Among the minor infections, Omphalitis was the commonest. Most of them (84\%) had foul smelling purulent discharge and periumbilical redness. Diagnosis of neonatal infection is one of the most difficult task in clinical medicine. Different authors have suggested several laboratory determinants ${ }^{33}$. Presence of neutrophil precursors is more suggestive of infection than the total differential count. Other authors demonstrated that a Low $\left(<15000 / \mathrm{cm}^{3}\right)$ or high $\left(>20,000 / \mathrm{cm}^{3}\right)$ WBC count were associated with neonatal infection ${ }^{34}$. In this series lowest WBC count was $8000 / \mathrm{cm}^{3}$. However a count over $20,000 / \mathrm{cm}^{3}$ was found in $37.5 \%$ cases. Thus in this series a high WBC was a useful indicator of infection. Culture of Umbilical swabs were done in all case of Omphalitis. In this study predominat organism were gram positive cocci. Staphylococcus aureus was found in $55.15 \%$ cases and $\mathrm{E}$. coli in $5.88 \%$. The findings contrasts to the earlier findings where E. coli was found in $55.6 \%$ and staph aureus in $20 \%$. On the otherhand it has similarities with the findings of Ahmed Haque et $\mathrm{al}^{35}$. In this series no group B streptococci was isolated. The etiology of neonatal seticaemia varies from country to country and from one hospital to the other. The difference is due to prevailing obstetric and nursery facilities and pattern of usage of antimicrobial agents. Blood culture done in 184 cases revealed positive culture in $41(22.28 \%)$ cases. Sinha et al reported an isolation rate of $28.08 \%$, Khatua et al found a much higher rate of isolation $(60 \%)$. This high rate of isolation could probably be due to the use of more sensitive media. Chest X-ray showing Unilateral and bilateral patchy opacities in various zones of lungs were the radiological evidence of presence of pneumonia. Most patients had received antibiotic prior to admission. More rate of isolation of organisms could be expected if prior antibiotics were not given. $20(6.25 \%)$ patients with neonatal infections died in the hospital, most of these cases were preterm-low birth weight and were hospitalized in a critical state of illness.

\section{Conclusion}

Neonatal sepsis still remains a dreaded disease. Preterm low birth weight, prolonged rupture of membrane, birth asphyxia, home delivery etc. were the 
important risk factors for infection. Septicaemia, pneumonia, meningitis, diarrhoea, UTI were the major infections presented either singly or in combination. Omphalitis was the commonest minor manifestation. Although this is a hospital based study in a referrel hospital, it has been able to findout the clinical pattern of neonatal infection. More extensive studies involving larger sample of neonates with good microbiological support is desirable to study the clinical pattern of neonatal infections in the country.

\section{Table-1}

Age and Sex Distributions ( $\mathrm{N}=320$.)

\begin{tabular}{|c|c|c|}
\hline Sex & Number & Percentage \\
\hline Male & 212 & 66.20 \\
\hline Female & 108 & 33.80 \\
\hline & 320 & 100.00 \\
\hline
\end{tabular}

Age Distributions

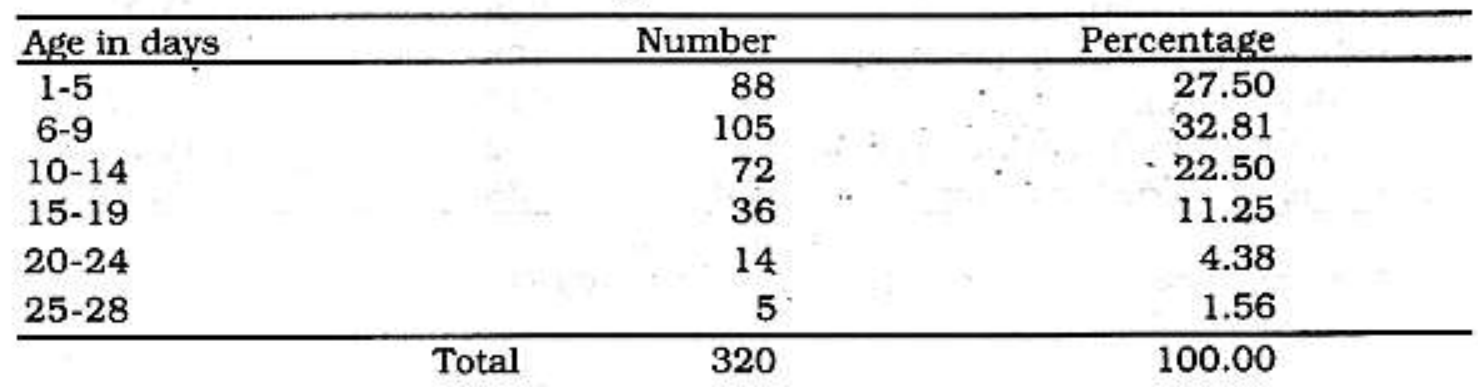

Table-II

Spectrum of Infection $(\mathrm{N}=320)$

\begin{tabular}{lrc}
\hline Infections & No. of cases & Percentage \\
\hline Major infections: & 118 & \\
Septicacemia & 70 & 36.87 \\
Pneumonia & 20 & 21.87 \\
Meningitis & 7 & 6.25 \\
Diarrhoea & 6 & 2.19 \\
UTI & & 1.87 \\
Minor infections : & 101 & \\
Omphalitis & 28 & 31.56 \\
Pemphigus & 7 & 8.75 \\
Conjunctivitis & & 2.19 \\
\hline
\end{tabular}

There were overlaping of major infections in some patients 
Table-III

Age at onset of Infections

\begin{tabular}{lccc}
\hline Type of Infection & Age (Hours) & Number & Percentage \\
\hline Major & $<48$ & 50 & 27.17 \\
$(\mathrm{~N}=184)$ & $>48$ & 134 & 72.83 \\
& & & \\
Minor & $<48$ & 55 & 40.44 \\
$\mathrm{~N}=136$ & $>48$ & 81 & 59.56 \\
\hline
\end{tabular}

\section{Table-IV}

Risk Factors for Infections

\begin{tabular}{lcc}
\hline Risk Factors & Number & Percentage \\
\hline 1. Preterm low birth wt. & 228 & 71.25 \\
2. Prolonged rupture of membrane & 108 & 33.75 \\
3. Birth Asphyxia & 46 & 14.37 \\
4. Home delivery Untrained person & 52 & 16.25 \\
5. Use of Unsterile blade for cutting cord. & 36 & 11.25 \\
\hline
\end{tabular}

There were more than one risk faefor in many subjects.

\section{Table-V}

Mode of Presentation

\begin{tabular}{lcc}
\hline Clinical Presentation & Number & Percentage \\
\hline Fever & 160 & 50.00 \\
Respiratory distress & 115 & 35.92 \\
Reluctant to feeds & 112 & 35.00 \\
Abdominal distension & 102 & 31.87 \\
Vomiting & 98 & 30.62 \\
Apnoeic spells & 28 & 8.75 \\
Jaundice & 36 & 11.25 \\
Foul smelling umbilical discharge & 80 & 25.00 \\
Hypothermia & 11 & 3.44 \\
Pemphigus & 28 & 8.75 \\
Convulsions & 20 & 6.25 \\
\hline
\end{tabular}


Organisms Isolated

\begin{tabular}{lrrrr}
\hline Culture & $\begin{array}{r}\text { Total No. of } \\
\text { Cases }\end{array}$ & $\begin{array}{r}\text { Positive } \\
\text { culture }\end{array}$ & $\begin{array}{r}\text { Organism } \\
\text { Isolated }\end{array}$ & Percentage \\
\hline MAJOR (N=184) & 184 & 41 & $\begin{array}{r}\text { E. coll } 35 \\
\text { Stap aureus } 6\end{array}$ & 19.02 \\
Blood & 184 & 15 & E. coli 15 & 3.26 \\
Urine & 160 & 6 & E. coli 6 & 3.15 \\
Stool & & & & 3.75 \\
Ni1NOR (N=136) & 136 & 83 & S. Aureus 75 & 55.15 \\
Umbilical swab & & & E. coll 8 & 5.88 \\
$\quad$ Swab from skin infections & 35 & 22 & S. Aureus - & 62.85 \\
\hline
\end{tabular}

Table-VI

Haematological Data in Infection

\begin{tabular}{lrcc}
\hline Haematological Data & Range & Number & Percentage \\
\hline TWBC & $8,000-10,000$ & 60 & 18.75 \\
& $10,000-20,000$ & 140 & 43.75 \\
& $20,000-30,000$ & 120 & 37.50 \\
\hline & Total & 320 & 100.00
\end{tabular}

Table-VII

CSF Study in Meningitis $(\mathrm{N}=20)$

\begin{tabular}{lcc}
\hline CSF & Number of Patients & Percentage \\
\hline Colour (Hazy) & 16 & 80 \\
WBC (Neutrophils) Plenty & 16 & 80 \\
ORGANISMS (Gram Stain) & & \\
Gram Positive & 6 & 30 \\
Gram Negative & 8 & 40 \\
No organisms & 6 & 30 \\
CULTURE & 20 & No growth \\
BIOCHEMISTRY & RANGE & MEAN \\
Protein mg/dl & $140-160$ & 152 \\
Sugar mg/dl & $15-35$ & 22 \\
\hline
\end{tabular}




\section{Table-IX}

Radilogical findings in Pneumonia $(\mathrm{N}=70)$

\begin{tabular}{|c|c|c|}
\hline Findings & Number & Percentage \\
\hline Bilateral patchy opacity in lung fields & 30 & 42.86 \\
\hline Opacity in the RT uooer and midzones & 16 & 22.86 \\
\hline Opacity in the RT upperzone of the lungs & 24 & 34.28 \\
\hline $\begin{array}{ll}\text { Total } \\
\end{array}$ & 70 & 100.00 \\
\hline
\end{tabular}

\section{References}

1. Behrman RE, Vaughan VC. Neonatal infection, In. Nelson's Textbook of Paediatrics. -14th ed, Philadelphia W. B. Saunders Company, 1987; 422-427.

2. Hutchinson $\mathrm{JH}$. Cockburn, F. Neonatal infection. In Practice of Paediatric Problem. 6th ed. P.G. Asian Economy 1986: 81-100.

3. Gotoff Sp. Behrman RE Neonatal Septicaemia. J Paediatr 1970: $76: 142-43$.

4. Siegeh JD, MC Craken GH. Sepsis neonatorum. N Eng J Med 1981: 304: 642-647.

5. Klein JO, Dashebsy B. Norton CRetal. Selection of antinicrobial agents for treatment of neonatal Sepsis Rev Infect Dis 1983: 5 (supply) : 555.

6. Narayann 1. Mitter A. Gujral V. A comparative Study on the value of Exchange and blood transfusion in the management of Severe neonatal Septicemia with Sclerema. Indian J Paediatr-1982-4a 519-527.

7. Hossain MM, Rashid MA, Neonatal Sepsis. Bangladesh J Child Health 1989: $13: 1-5$.

8. Nayer RL. Causes of the excessive rates of perinatal and prematurity in pregnancies complicated by maternal Urinary tract infections. N Eng J. Med 1979; 300: 819822.

9. Baker CJ, Kasper Dl. Correlation of maternal antibody deficiency with susceptibility to Neonatal Group B Sreptococcal infection. N Eng. J med 1976; 294: 753-756.

10. Guba DK. Dalbir J, Krishna MS etal Outcome of neonatal septicemia. A Clinical and bacteriological profile. Indian Pediatr. 1978; 15: 423-7.

11. MC Cracken G-H, Shinefield HR. Changes in the pattern of neonatal septicemia and meningitis. Am. J. Dis child 1966-112:33-39.

12. Bavikatte K, Schreiner RL, Lemons JA, Gresham EL, Group D streptococcal septicemia in the neonate Am. J. Dis Child 1979;113: 493-496.

13. Bhakoo ON, Agarual KC, Narang A, Bhattacharie, Prognosis and treatment of Neonatal Septicemia- A clinico- bacteriological study of 100 cases. Indian Pediatr. 1974; 11 : 519-524.

14. Buetow KC. Klein SW, Lane RB. Septicemia in Premature infants. AM. J. Dis. Child 1965; $110: 29-41$.

15. Webber S. Wilkinson AIR etal. Neonatal Pneumonia, Arch. dis Child 1990; 65 : 207211.

16. KLein Jo. Bacterial infections of the respiratory tract. In Remington. JS. Klein Jo. Editors. Infections Diseases of fetus \& Newborn 2nd ed. Philadelphia W.B. Saunders Company 1983; 744-752.

17. Behrman RE. Vaughan VC. Meningitis. In Nelsons Textbook of Paediatrics 14th ed. Philadelphia-WB. Saunders Company 1992; 506-507.

18. Winberg J. Epidemiology of Symptomatic Urinary tract infection in child hood. Acta Paediatr Scand 1974; 252 (Suppl). 
19. Little wood NM, 66 infants with urinary tract infection in first month of life. Arch dis Child 1972: $47: 218$.

20. Henry FJ. Barthelemew RK et al. Epidemiology and transmission of rotavirus infection in West Indtes. W I Med J 1990: 39:205-211.

21. Chamberlin JW. Omphalitis in Newborn J Paediatr. $1936: 215-222$.

22. Clushing A. H. Omphalitis A review. Paediatr Infect dis 1985; $4: 282-286$.

23. Schlegel RL. Bellande JA Increased Susceptibility of male to infection, Lancet 1969; $2: 826$.

24. Malik MA Etiology and hospital outcome of omphaliltis in hospitalised neonates in a city hospital (Dissertation) Dhaka, College of Physicians and Surgeons-1991).

25. Fairchild JP. Greber Cd. Vogel EH etal. Flora of Umbilical Stump. J. Paediatr 1958; 53: $538-546$.

26. Khatua Sp, Das Ak Chattergee B et al, Neonatal Septicaemia, Indian J Paediat 1986; $33: 509-514$.

27. Charles M. Ginsburg Gerrge Metal, Urinary tract infection in Young infants, Paediatrics 1982: 69 .

28. Behrman RE. Vaughan VC Neonatal infection. In. Nelsons Textbook of paediatics 14th ed Philadelphia, WB, Saudars Company $1992: 495-507$.

29. Watkins JB Sunaryo FP. Farrain SH Hepatic manifestation of Congenital perinatal disease. CIM Perinatal 1981: $8: 407-480$.

30. Feigin Rd, Coliagram DL Postnatally acquired infections In. Diseases of Foetus and Infant Mostby Company 1983: 650-690.

31. Chambarlin JW Omphalitis in Newborn J. of Paidiatric $1936: 9: 215-222$.

32. Bakul Kantidev etal Clinical profile of neonatal infection in IPGM\&R. Study of 100 cases. Dissertation submitted for fulflment of FCPS Part II Ped, Bangladesh College of Physician \& Surgeons.

33. Marwana N. Marwana RK etal Routine haematological Values in term newborn, Indian Paediatr $1992: 29$.

34. Philip AGS. Hewitt JR. Early diagnosis of neonatal sepsis Paediatrics 1980; 65 : 1036.

35. Ahmed Ifteqar etal Studies of neonatal Septicamia (Disertation) submitted for partial fulfilment of FCPS Part-II Paediatrics, 1991. BCPS, (Bangladesh College of Physician and Surgeon). 